\title{
A TIPOLOGIA PLUVIOMETRICA DE BAURU/SP
}

\author{
PINHEIRO, Gabriela Marques - gabimpinheiro20@hotmail.com \\ DANNI-OLIVEIRA, Inês Moresco - inesmdo10@gmail.com \\ LABOCLIMA/UFPR - Univ Fed do Paraná
}

\begin{abstract}
RESUMO. Os problemas ambientais são todos aqueles que afetam negativamente a qualidade de vida dos indivíduos no contexto de sua interação com o espaço, seja ele natural ou social. Dentre estes problemas ambientais, encontrase inserido os impactos de ordem extrema, em especial aqueles oriundos da atmosfera, que afetam de maneira inesperada o ambiente. Desta forma o presente trabalho teve como objetivo o estudo da tipologia pluviométrica da cidade de Bauru por meio de uma análise temporal das chuvas ocorridas nos meses de maior precipitação, para o período de 1978 a 2008.0 uso de tipologias climáticas constituiu-se em eficiente proposta de analise como meio de informação para a caracterização do ritmo pluviométrico de dado lugar. Dessa forma conclui-se que houve leve tendência de aumento nos totais de precipitação nos últimos trinta anos de análise a partir da linha de tendência linear, porem em relação a sua media móvel, esta sofreu oscilações ao longo de sua historia principalmente na década de 2000, onde observou-se uma ligeira queda.

Palavras-chave: tipologia, pluviosidade, Bauru.
\end{abstract}

THE RAINFALL TYPOLOGY OF BAURU/SP

ABSTRACT. Environmental problems are those that negatively affect the quality of life of individuals in the context of its interaction with the space, be it natural or social. Among these environmental problems, is inserted into the impacts of extreme order, in particular those from the atmosphere, which unexpectedly affect the environment. Thus the present study aimed to study the rainfall typology of Bauru, through a temporal analysis of rainfall occurring in the months of highest rainfall for the period 1978 to 2008. The use of weather types consisted in analyzing proposed as efficient means of information to characterize the rhythm of rainfall. Thus we conclude that there was a slight upward trend in total precipitation over the past thirty years of analysis through the linear trend line, however, in relation to its moving average, it has undergone variations throughout its history mainly in the 2000's where there was a slight drop.

Key-words: Typology, Rainfall, Bauru.

\section{INTRODUÇÃO}

As cidades constituem a forma mais radical de transformação da paisagem natural (LIMA, 2010). Atualmente podem ser definidas como sistemas complexos e caracterizadas pelo processo contínuo de mudança, pois são consideradas abertas aos fluxos de massa e energia e possuem importância demográfica, socioeconômica e cultural.

No Brasil, entre as décadas de 1950 a 1980, ocorreu expressivo crescimento da população citadina, sustentando-se principalmente na industrialização, que gerou um rápido aumento produtivo e levou o homem do campo para as cidades. Os dados do Instituto Brasileiro de Geografia e Estatística - IBGE (Censo 2010) confirmam tal fato, pois, em 1940 a população residente em áreas urbanas era de $34,3 \%$, enquanto em 2010 passou a $81,25 \%$.

O processo de ocupação dessas áreas juntamente com a expansão da população fez com que as cidades brasileiras de grande, médio e pequeno porte crescessem com planejamento ambiental pouco eficiente e insuficiente para atender a demanda populacional e sem políticas públicas que visassem seu desenvolvimento.

Como consequência dessa transformação da natureza em ambiente urbano, gerou-se um espaço eminentemente antropizado que se fez acompanhar por uma cadeia complexa de problemas inter-relacionados.

Dentre eles, destacamos eventos de pluviosidade intensa que atacam a integridade urbana, causando transtornos à circulação de transportes e pessoas, a comunicação, as atividades e serviços e ainda problemas vinculados a saúde da população citadina.

Desta forma o ritmo dos elementos climáticos influencia, tanto direta quanto indiretamente a organização de uma sociedade, sejam essas anomalias negativas ou positivas em relação aos valores médios (SORRE, 1984). O conceito de clima para Sorre é fundamental para o entendimento de ritmo climático e da tipologia pluviométrica, pois este considera as propriedades formadoras dos tipos de tempo, como a temperatura, umidade, precipitação, 
etc., interagindo com as características dos lugares, desta forma contemplando situações atmosféricas habituais e excepcionais. O autor buscou salientar o caráter dinâmico das propriedades meteorológicas, introduzindo as noções de variações e ritmo na sucessão dos tipos de tempo, considerando desta forma que os estados da atmosfera se desenvolvem em uma sequência rítmica. (TARIFA, 1975, p.12)

Sendo assim o evento é considerado como anomalia positivo quando contribui de forma apropriada. Podemos citar como exemplo o aumento da sanidade em ecossistema causado por inundações periódicas, ou ate a despoluição da atmosfera de um determinado local em virtude de um impacto pluvial (MONTEIRO, 1991). Os eventos extremos negativos impõem graves danos à infraestrutura física e de serviços (entre outros), tornando assim critica as condições de vida da população neste ambiente.

As interações entre as anomalias positivas de precipitação e as cidades desprovidas de um planejamento urbano adequado resultam em um produto negativo inerente à população residente - os impactos pluviométricos urbanos. Tais impactos são provocados, principalmente, pela inadequação do uso e da ocupação dos solos nas cidades, que, por meio do processo desordenado e acelerado da urbanização, produzem rugosidades favoráveis e fundamentais para suas ocorrências. Tal realidade urbana vem intensificar os impactos pluviométricos urbanos que são desencadeados pela ocorrência das anomalias naturais.

Os eventos de pluviosidade extrema caracterizam-se por possuírem caráter altamente dinâmico, apresentando um rompimento na variabilidade natural do ritmo, no qual se inserem os eventos extremos e excepcionais.

Para Gonçalves (2003) os eventos extremos tornam-se risco quando superam a capacidade material de determinada organização social para absorver, amortizar ou evitar seus efeitos negativos e tornam-se catastróficos. Essa situação pode ser desencadeada não somente por um evento extremo, mas, também, pelo evento normal, sendo este fato que determina o grau de vulnerabilidade o qual esta sociedade esta inserida. De acordo com o IPCC (2001) a vulnerabilidade pode ser definida como o grau de suscetibilidade de um sistema, ou o quanto ele é incapaz de enfrentar efeitos adversos. É uma fusão entre a natureza, a magnitude e o percentual de uma variação dos quais o sistema é exposto, sua sensitividade e sua capacidade adaptativa.

Diante desta situação, os eventos climáticos extremos apresentam-se entre as causas deflagradoras de catástrofes naturais que atingem a sociedade.

Os regimes pluviométricos e térmicos, além de sua variabilidade natural, são os mais afetados pelas transformações da superfície terrestre, passando a exercer comportamentos irregulares, marcados por alternâncias de períodos chuvosos e secos, quentes e frio, responsáveis por inúmeras repercussões de ordem calamitosas sobre os mais variados espaços geográficos (SILVA, 2007).

Desta forma, esta pesquisa teve como objetivo o estudo da tipologia pluviométrica como proposta de análises do ritmo climático/pluvial na cidade de Bauru/SP. A importância deste procedimento é compreender as características e a distribuição temporal das precipitações no ambiente urbano de uma cidade de médio porte.

\section{A PRODUÇÃO DO ESPAÇO URBANO DE BAURU /SP}

O século $X X$ foi marcado por uma alta concentração humana nas cidades. A densidade populacional e a concentração de pessoas nestes espaços fizeram com que houvesse uma grande transformação do ambiente natural, com o uso cada vez mais intenso de recursos naturais. Neste contexto social e ambiental, as cidades atingiram o patamar central dos conflitos existentes entre a sociedade e a natureza.

A exemplo de várias cidades de médio porte, Bauru vem presenciando um rápido crescimento demográfico nas últimas décadas. A cidade expandiu-se muito nas décadas de 1950, 60 e 70, considerando o aparecimento de novos loteamentos, que incorporaram os elementos naturais 
da cidade, como os córregos que passaram a fazer parte da malha urbana, assim construindo um ambiente impermeabilizado, que altera o escoamento natural das águas pluviais. A tabela 1 mostra o crescimento demográfico da cidade de Bauru a partir da década de 1950 que apresentava uma população de 51.734 e atualmente apresenta 335.888.

Tabela 01

\section{Evolução Populacional por década da cidade de Bauru}

\begin{tabular}{|c|c|}
\hline Décadas & População Urbana \\
\hline 1910 & 3.000 \\
\hline 1920 & 15.000 \\
\hline 1930 & 22.733 \\
\hline 1940 & 32.796 \\
\hline 1950 & 51.734 \\
\hline 1960 & 85.237 \\
\hline 1970 & 120.178 \\
\hline 1980 & 180.761 \\
\hline 1991 & 255.669 \\
\hline 2000 & 316.064 \\
\hline 2010 & 344.039 \\
\hline
\end{tabular}

Fonte: Plano Diretor 1996 e Censo 2010. Elaboração: Pinheiro, 2011.

Essa expansão urbana acarretou impactos socioambientais, pela ineficácia nas ações de controle, ligadas ao planejamento urbano, baseado, muito mais, num imediatismo e na valorização do ambiente construído em relação ao ambiente natural.

A natureza na cidade passou por um processo acentuado de descaracterização e degradação. Conforme levantamento de campo de Santos \& Vitte (2004), esses consideram que os principais problemas ambientais observados e que atualmente se manifestam nesta cidade, são as erosões do solo, assoreamento dos cursos d'água, inundações urbanas, destruição da cobertura vegetal, urbanização em áreas de risco, ocupação urbana em áreas de preservação permanente e depósitos tectogênicos para aterro de voçorocas.

Muitos destes problemas estão vinculados ao ritmo pluviométrico da cidade. A ocorrência e o aumento das áreas de enchentes é um desses e interfere diretamente na habitação, em determinadas áreas consideradas de risco; na circulação, obstruindo ruas e avenidas, pela força da água e, no uso das verbas públicas, já que muitos casos são resolvidos sem considerar perspectivas futuras de crescimento da área urbana, prolongando o aumentando gastos para o poder público. Outro problema vinculado a este seria o lançamento de esgotos residenciais, comerciais e industriais, lixo, além da erosão e assoreamento da Bacia Hidrográfica do Rio Bauru com seus afluentes - Água da Ressaca, Água da Forquilha, Água do Sobrado, Córrego da Grama, Córrego do Castelo, Córrego Barreirinho e Córrego Vargem Limpa, pela margem esquerda, Ribeirão das Flores, Córrego Água Comprida e Ribeirão Vargem Limpa pela margem direita que estão completamente inseridos na área urbana e intensamente degradados (CATELAN, 2006). 


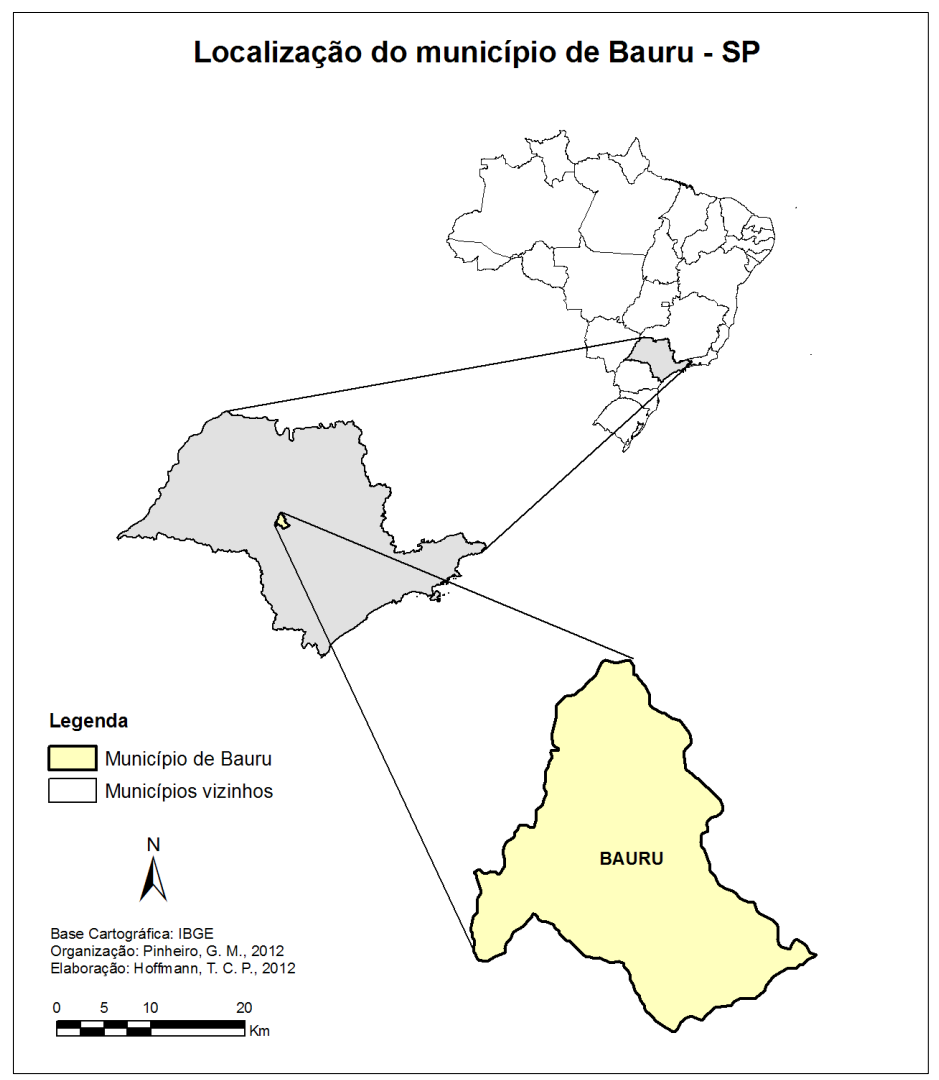

Figura 1: Localização do Município de Bauru

Desta forma conclui-se que a cidade de Bauru encontra-se degradada em relação ao ambiente natural. Muitos destes problemas ambientais surgiram desde que a cidade se assentou sobre um espaço topográfico, antes estritamente com características e dinâmicas naturais, de modo que muitas áreas ocupadas são impróprias à moradia como as margens dos rios e as vertentes muito íngremes. Cabe lembrar que Bauru se originou na confluência do Rio Bauru e Córrego das Flores. A área urbana passou a ocupar toda a bacia do rio Bauru com modificações na paisagem natural e com as canalizações dos córregos Bauru e Flores. Frente a essa expansão, Bauru apresenta vários problemas no ambiente urbano, oriundos da ineficácia de seu planejamento por não estabelecer parâmetros eficientes para a produção do espaço urbano da cidade, como consequência de diversos fatores políticos e econômicos pertinentes as várias gestões municipais, estaduais e federais.

\section{PRESSUPOSTOS TEÓRICOS METODOLÓGICOS}

Neste trabalho a elaboração do pensamento conduziu-se por meio de uma análise sistêmica e integrada, onde o clima é considerado como um sistema aberto, adaptativo e complexo, cuja vitalidade esta na dependência direta da capacidade de trocar energia e matéria com o exterior. Encarando este como um sistema aberto e adaptativo é possível que haja uma multiplicidade no seu estado de equilíbrio, integrando a participação do homem e da natureza como resultado geral.

Monteiro (1976) propõe uma abordagem sistêmica valorizando a disposição das partes e dos elementos no conjunto, relacionados entre si, desenvolvendo uma estrutura organizada que se adapta e produz novos padrões e articulações entre as escalas.

Dentro desta perspectiva da climatologia, Monteiro (1976), sugeriu uma hierarquização dos subsistemas climáticos, onde estes se encontram integrados através da troca dos fluxos de energia e de matérias neles contidas. Para o autor o sistema climático possui uma estrutura global, onde estes estão organizados horizontalmente (estrutura) e verticalmente (função). 
Esta estrutura recorre a ideia de uma árvore com suas ramificações (Figura 2), e esta representação foi dada, pois expressa dinamicidade e por revelar as relações entre partes e, sobretudo por admitir implicitamente a noção de crescimento e evolução do sistema. Dentro desta estrutura esta contida os subsistemas zonal (diversificação do todo), regional (organização espacial das unidades climáticas) e local (especialização do todo).

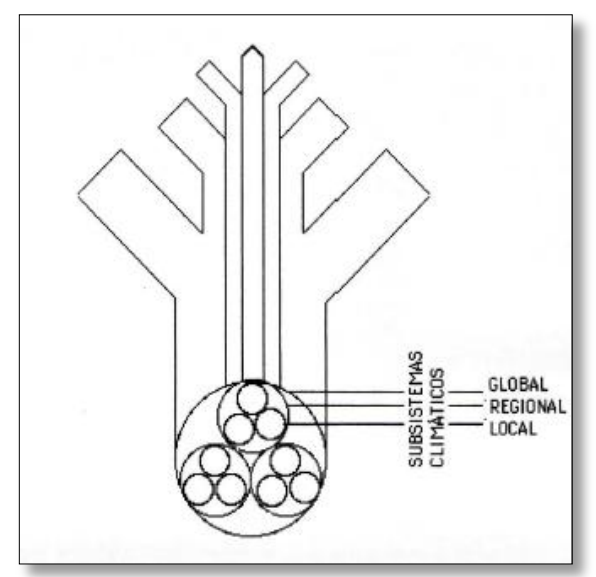

Figura 2: Perspectiva Sistêmica da Climatologia. Fonte: Koestler, 1971. In: Monteiro, 1976

Nesta pesquisa utilizou-se a estrutura apresentada acima como escala espacial do trabalho, apoiando-se na idéia da hierarquização do clima e que estes encontram-se articulados e interligados. A escala espacial utilizada nesta pesquisa será a local.

Ainda dentro deste referencial teórico, esta pesquisa foi baseada no método de análise de Monteiro (1976), que aplicando as noções de funcionalidade sistêmica, formaliza uma estrutura teórica e metodológica para a compreensão do fato urbano, o S.C.U. (Sistema Clima Urbano). O autor aborda o clima como sendo "um sistema singular, aberto, evolutivo, adaptativo e morfogênico, composto pelo clima local e pela cidade". Este pensamento foi embasado a partir de reflexões em relação à Teoria Geral dos Sistemas (TGS).

Para melhor aprimoramento deste Sistema Clima Urbano, Monteiro (1976) propõe para os estudos de clima urbano considerem-se três canais de percepção humana: Termodinâmico (coparticipação do homem-natureza - conforto térmico), Físico-Químico (responsabilidade humana - qualidade do ar) e Hidrometeórico (natureza -impacto meteórico), sendo o último de maior interesse para esta pesquisa.

O Canal de Percepção Humana III - impacto meteórico, Subsistema Hidrometeórico, foi escolhido por abarcar/tratar das chuvas e seus impactos urbanos. Este Canal de Percepção trabalha preferencialmente com as sucessões dos estados atmosféricos extremos e violentos do ritmo climático, gerando uma irregularidade da frequência temporal, distribuição espacial e intensidade das chuvas extremas ou da ausência de chuvas.

O subsistema hidrometeórico (estudo do comportamento dos dados pluviométricos), a responsabilidade dos impactos ocorridos no ambiente urbano em eventos pluviais extremos, nesta pesquisa, vem da natureza com forte influencia social e econômica - trânsito no subsistema do operador ao operando - sendo que, para este estudo, as atividades econômicas e sociais desordenadas criam áreas urbanas favoráveis para que os impactos pluviométricos ocorram, ou seja, este processo juntamente com a presença das anomalias pluviais positivas, é o principal responsável por tais interferências.

As manifestações meteóricas de impacto são eventos que possuem variações extremas e formas violentas do ritmo - desvio dos padrões habituais, disritmias -, provocadas pela sucessão dos estados atmosféricos. Dentro destas manifestações estão inseridos os de ordem extrema, ocasionando danos as áreas de incidência geralmente ocupadas por atividades 
humanas, e estes podem ser representados pela avalanche (neve), nevoeiros, secas, enchentes, granizos, geadas, escorregamento de vertentes, descargas elétricas, tornados e vendavais, sendo que na maioria das vezes estes elementos estão associados ao fenômenos atmosféricos.

Estes eventos extremos caracterizam-se por serem altamente dinâmicos e possuírem uma variabilidade natural em seu ritmo, afastando-se da media normal e ocorrendo com menos frequência.

Este canal possui forte vinculo com a circulação atmosférica regional e seus tipos de tempo especiais (disritmias extremas). Essas intensas chuvas atingem o ambiente transformado pelo homem que, dependendo da maneira do uso e da ocupação do solo, facilitam a ocorrência de impactos na área urbana.

\section{PROCEDIMENTOS TÉCNICOS}

Os dados de precipitação foram obtidos junto ao Instituto de Pesquisa Meteorológicas (IPMet) na cidade de Bauru e foram analisados no período entre 1978 a 2008, para os meses de dezembro, janeiro e fevereiro, comumente os mais chuvosos.

Estes dados foram tratados estatisticamente no programa Microsoft Office Excel, calculando-se os totais, as médias, os desvios padrões positivo e negativo e o coeficiente de anomalia. $O$ desvio padrão é uma medida do grau de dispersão dos valores em relação ao valor médio (a média).

Já o coeficiente de anomalia calcula o "desvio" do valor observado com respeito à sua média histórica. Este coeficiente expressa de maneira clara, os eventos extremos para cada período, auxiliando assim na interpretação dos sistemas climáticos atuantes e suas repercussões pluviométricas. Este tipo de calculo foi escolhido, pois coincide com o pensamento central da pesquisa, que tem como intuito trabalhar com o ritmo climático e não somente com as medias. Para alcançar o coeficiente de anomalia foram utilizadas as seguintes fórmulas.

$$
\begin{gathered}
\text { Média } \bar{x}=\frac{\sum x_{i}}{n} \\
\text { Desvio Padrão } s^{2}=\frac{\sum\left(x_{i} \bar{x}\right)^{2}}{n}
\end{gathered}
$$

Anomalia $\alpha=x_{m}-\bar{x}$

\section{Legenda}

$$
\begin{array}{ll}
\bar{x}=\text { média } & \alpha=\text { anomalia } \\
x_{i}=\text { soma.dos.elementos } & \begin{array}{l}
x=\text { dados.mensais } \\
n=\text { número.de.elemnetos }
\end{array} \\
s=\text { desvio.padrão } & \bar{x}=\text { média.total.mensal }
\end{array}
$$

Posteriormente, baseado na técnica de escolha de anos-padrão, aplicado por Monteiro (1976), adaptado por Boin (2000), criou-se uma tipologia pluviométrica para o município fundamentada nas oscilações rítmicas que desviaram do habitual, recorrendo aos coeficientes de anomalia e desvio padrão. Dentro desta caracterização possibilitou-se a delimitação dos meses em: Normais Tendentes a Seca (Ns), Normais Tendentes a Chuvosa (Nc), Secas (S) e Chuvosas (C). 


\section{RESULTADOS}

Os dados pluviométricos tornam-se importantes na análise dos resultados desta pesquisa, pois estes permitem uma compreensão matemática da quantidade, periodicidade e intensidade dos fenômenos ocorrentes na cidade de Bauru. Desta forma, as taxas numéricas de precipitação são fundamentais neste estudo de caso, correspondendo a análise de suas variações ao longo do tempo, dando base para as explicações das variações rítmicas existentes.

Os gráficos 01 e 02 foram confeccionando representando o total sazonal de pluviosidade para os meses de dezembro, janeiro e fevereiro (1978 a 2008). Estes gráficos foram gerados com o intuito de analisar os anos-padrões os quais se baseiam nos coeficientes positivos e negativos dos desvios padrões. Nota-se que os anos de 1986/1987 e 1992/1993 representaram os anos chuvosos, assim como os anos de 1978/1979, 1979/1980, 1980/1981, 1985/1986, 1987/1988, 1991/1992, os anos secos, tanto para o calculo dos desvios padrões, assim como nos cálculos de anomalia. A utilização dos dois métodos permite verificar não só a variação temporal como também o grau de desvio dos episódios extremos.

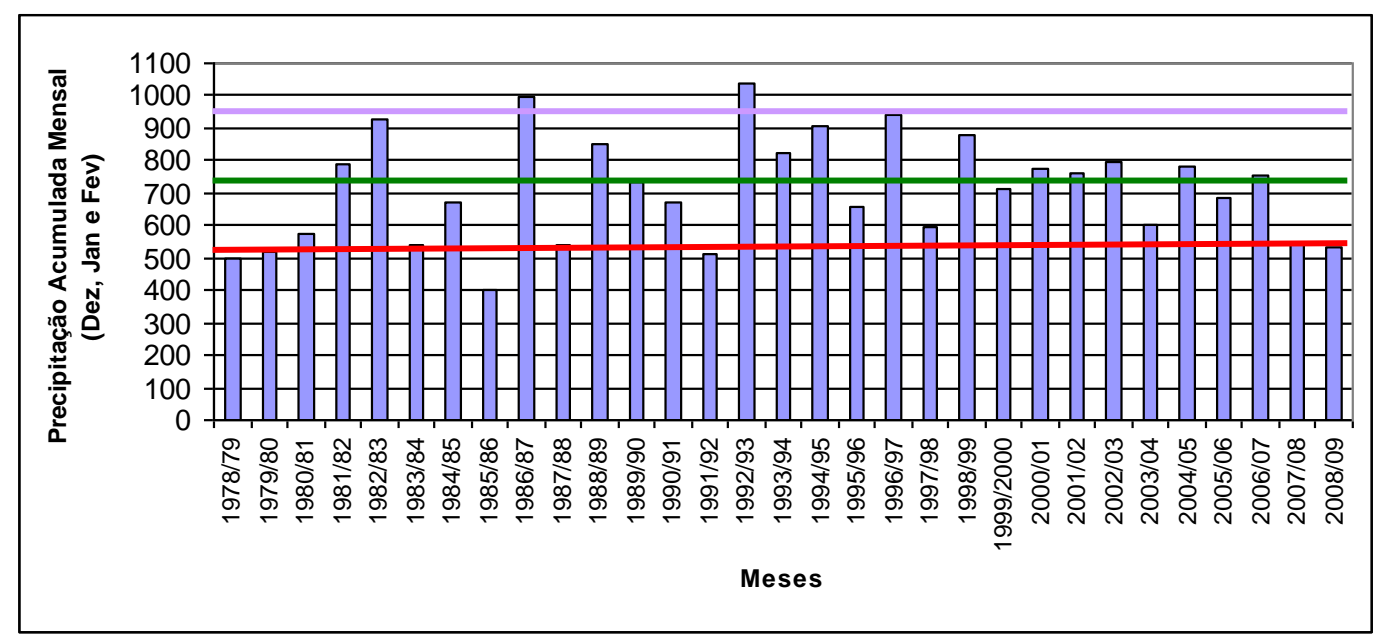

Gráfico 01. Média, desvio padrão positivo e negativo para o total dos meses de Dezembro, Janeiro e Fevereiro de 1978 a 2009. Fonte: IPMet.

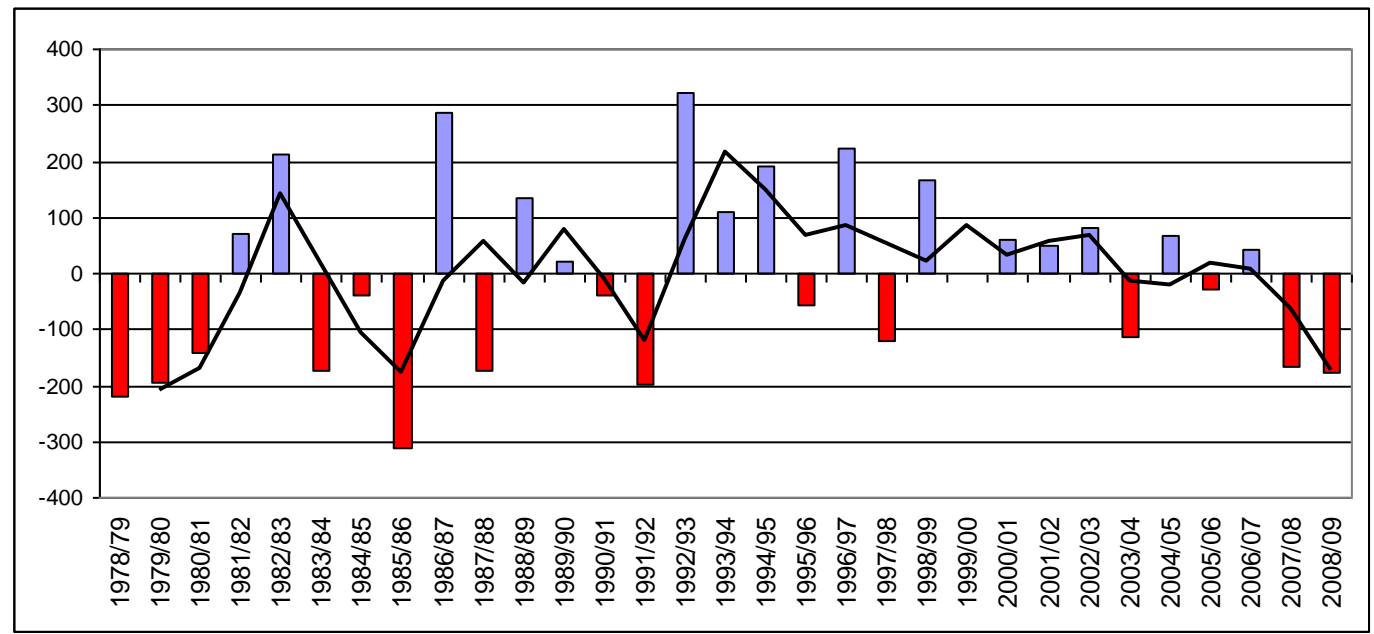

Gráfico 02. Grau de anomalia total dos meses de Dezembro, Janeiro e Fevereiro de 1978 a 2009. Fonte: IPMet.

Sendo assim, fundamentado na proposta de anos-padrão de Monteiro (1976) adaptada por Boin (2000), pode-se criar uma tipologia pluviométrica para o município (tabela 02). A utilização desta técnica possibilitou a classificação das estações estudadas objetivando a investigação sazonal das precipitações representativas. 
Desta forma criou-se o quadro síntese da tipologia pluviométrica do município de Bauru/SP, para o período pesquisado. Segundo a tipologia proposta por Monteiro (1976) os coeficientes positivos e negativos, possibilitaram a classificação sazonal em:

Chuvoso (C) - Esta classificação revela anomalias com valores positivos, iguais ou superiores ao desvio padrão positivo. Estes estão representados pela cor azul escura.

Seco (S) - Esta classificação revela anomalias com valores negativos, iguais ou superiores ao desvio padrão negativo. Estes estão representados pela cor vermelha.

Normais Tendentes a Chuvosa (Nc) - Apresentam anomalias que estão representadas entre a média e o desvio padrão positivo. Estes estão representadas pela cor azul claro.

Normais Tendentes a Seca (Ns) - Apresentam anomalias que estão representadas entre a média e o desvio padrão negativo. Estes estão representadas pela cor laranja.

Tabela 2

Ano Normais Tendentes a Seca (Ns), Normais Tendentes a Chuvosa (Nc), Secas (S) e Chuvosas (C), para Dezembro, Janeiro e Fevereiro

\begin{tabular}{|c|c|c|c|c|c|c|c|c|c|}
\hline \multicolumn{7}{|c|}{ Tipologia Pluviométrica para os meses dezembro, janeiro e fevereiro (1978 a 2008) } \\
\hline $1978 / 79$ & $1979 / 80$ & $1980 / 81$ & $1981 / 82$ & $1982 / 83$ & $1983 / 84$ & $1984 / 85$ & $1985 / 86$ & $1986 / 87$ & $1987 / 88$ \\
\hline S & S & S & Nc & Nc & S & Ns & S & C & S \\
\hline $1988 / 89$ & $1989 / 90$ & $1990 / 91$ & $1991 / 92$ & $1992 / 93$ & $1993 / 94$ & $1994 / 95$ & $1995 / 96$ & $1996 / 97$ & $1997 / 98$ \\
\hline Nc & Ns & Ns & S & C & Nc & Nc & Ns & Nc & Ns \\
\hline $1998 / 99$ & $1999 / 00$ & $2000 / 01$ & $2001 / 02$ & $2002 / 03$ & $2003 / 04$ & $2004 / 05$ & $2005 / 06$ & $2006 / 07$ & $2007 / 08$ \\
\hline Nc & Ns & M & Ns & Nc & Ns & Nc & Ns & Ns & Ns \\
\hline
\end{tabular}

Fonte: IPMet. Elaboração: Pinheiro 2011.

Completando a análise, a tabela 03 apresenta a frequência porcentual das estações segundo sua tipologia pluviométrica. As estações sem anomalias pluviais (Tendente a seco, Tendente a Chuvoso e Médio), representaram $70 \%$ do total do período, principalmente entre os anos de 1993/1994 a 2007/2008. Já os períodos classificados como Chuvosos (C) e Secos (S), representaram $30 \%$ do total, sendo que apenas $6,6 \%$ destes eventos são classificados como chuvosos. A ocorrência destes compreende o período de 1978/79 a 1992/93.

Tabela 03

Frequência porcentual da tipologia pluviométrica

\begin{tabular}{|c|c|c|c|}
\hline Tipos & $\begin{array}{c}\text { Numero de } \\
\text { Ocorrência }\end{array}$ & Porcentagem & $\begin{array}{c}\text { Ordem de } \\
\text { Freqüência }\end{array}$ \\
\hline Seco (S) & 7 & $23,3 \%$ & $2^{\circ}$ \\
\hline Tendência a Seco (Ts) & 11 & 36,6 & $1^{0}$ \\
\hline Chuvoso (C) & 2 & $6,6 \%$ & $4^{\circ}$ \\
\hline Tendência a Chuvoso (Tc) & 9 & $30 \%$ & $3^{\circ}$ \\
\hline Médio (M) & 1 & $3,3 \%$ & $5^{\circ}$ \\
\hline Total & 30 ocorrências & $100 \%$ & \\
\hline
\end{tabular}

Após a classificação da tipologia pluviométrica achou-se necessário a elaboração do gráfico 03, o qual expressa as linhas de tendência linear e poligonal, de acordo com o procedimento dos 
totais de precipitação sazonal. Este gráfico é de grande importância, pois demonstra a tendência e a variabilidade da precipitação na cidade ao longo dos 30 anos de análise.

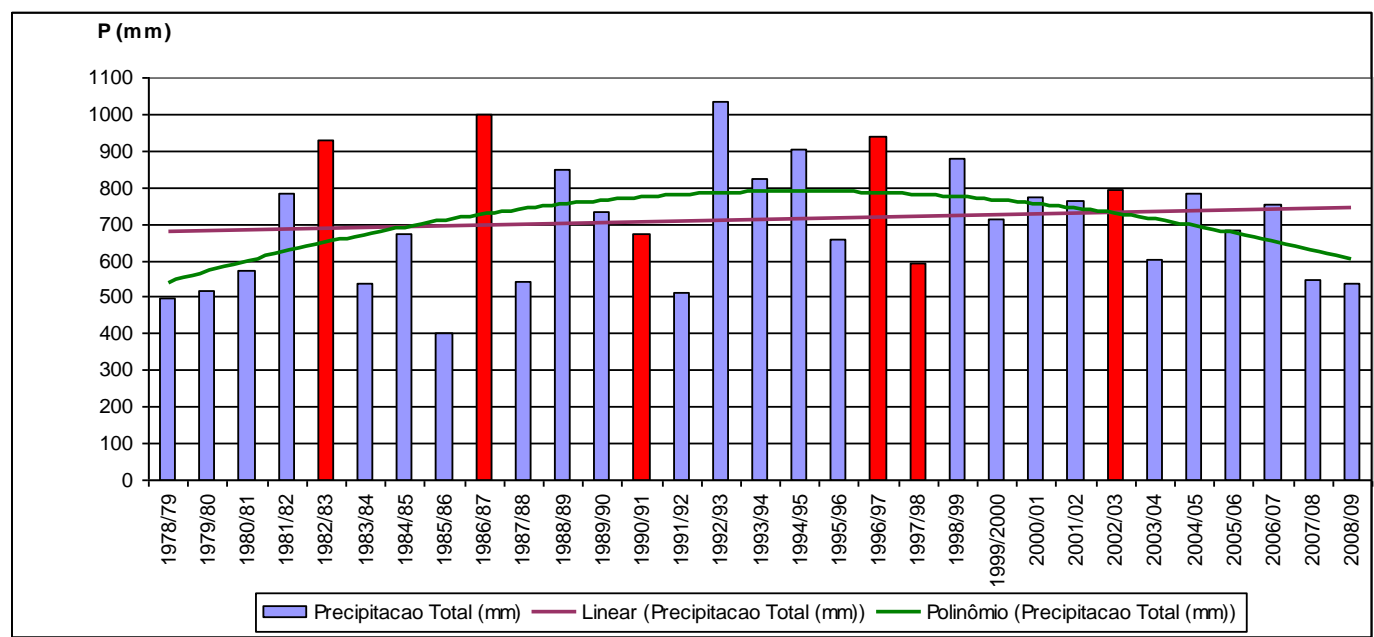

Gráfico 03. A tendência de precipitação para dez, jan e fev entre os anos de 1978 a 2008 As barras em vermelho correspondem a anos de El Niño.

Fonte: IPMet.

Antes da análise do gráfico 03, é de suma importância destacar o conhecimento da periodicidade da atuação do El Niño-Oscilação Sul (ENOS) no Brasil, visto que segundo Mendonça e Danni-Oliveira (2007) o mesmo "[...] provoca graves perturbações climáticas (secas anormais ou, ao contrario, ciclones e chuvas com totais pluviométricos extremamente elevados em relação as normais locais e regionais) em regiões habitualmente isentas de tais eventos. De acordo com os autores, registrou-se a influencia desses fenômenos nos seguintes anos: 1941/1942, 1951, 1953, 1957/1958, 1965, 1969, 1972/1973, 1976, 1982/1983, 1986, 1991, 1997/1998, 2002/2003 (destaque próprio)

Os anos destacados acima (em negrito) e no gráfico 03 (em vermelho) representam os anos de El Niño-Oscilação Sul (ENOS) na cidade de Bauru, observados pelo aumento e diminuição nos totais pluviométricos, como os anos de 1981/82, 1986/87, 1990/91, 1996/97, 1997/98 e 2002/02.

Ainda, segundo os autores, os anos de 1982/1983, representaram o período de El Niño mais intenso do século apresentando alto numero de impactos. Tal fato explica o grande desvio do total de precipitação no gráfico 01 , sendo este período um dos mais chuvosos registrando $927 \mathrm{~mm}$.

Nota-se no gráfico 03 que a cidade de Bauru registrou uma leve tendência ao aumento nos totais de precipitação nas estações de verão nos últimos 30 anos, segundo a linha de tendência linear, porém a linha de tendência poligonal aponta uma diminuição a partir da década de 2000. É de grande importância ressaltar que este fato não quer dizer precisamente que ocorreram mais eventos extremos, mas sim, anomalias que influenciaram, positivamente, as condições pluviométricas.

Desta forma tornou-se necessário analisar os eventos de pluviosidade ocorridos em cada mês separadamente, buscando a melhor representação de sua periodicidade e anomalias encontradas durante toda a serie histórica.

Observou-se que o mês de dezembro apresentou duas situações chuvosas extremas, correspondente aos anos de 1986/87 e 1991/1992. Conforme a discussão abordada acima, estes foram anos de El Niño-Oscilação Sul (ENOS), influenciando de forma positiva nas variáveis de precipitação. Comparando os dados mensais de dezembro com os de anos padrões de análise, nota-se que o ano de 1986/87 foi considerado chuvoso e o ano de 1991/1992 foi considerado seco. 
Já no gráfico 05, que demonstra a anomalia para a serie histórica de dezembro, observou-se que a reta de tendência poligonal, confirma uma leve diminuição nos totais de precipitação para o mês nos últimos 30 anos, assim como o gráfico 03, que registrou uma leve tendência a diminuição nos totais de precipitação nos últimos 30 anos.

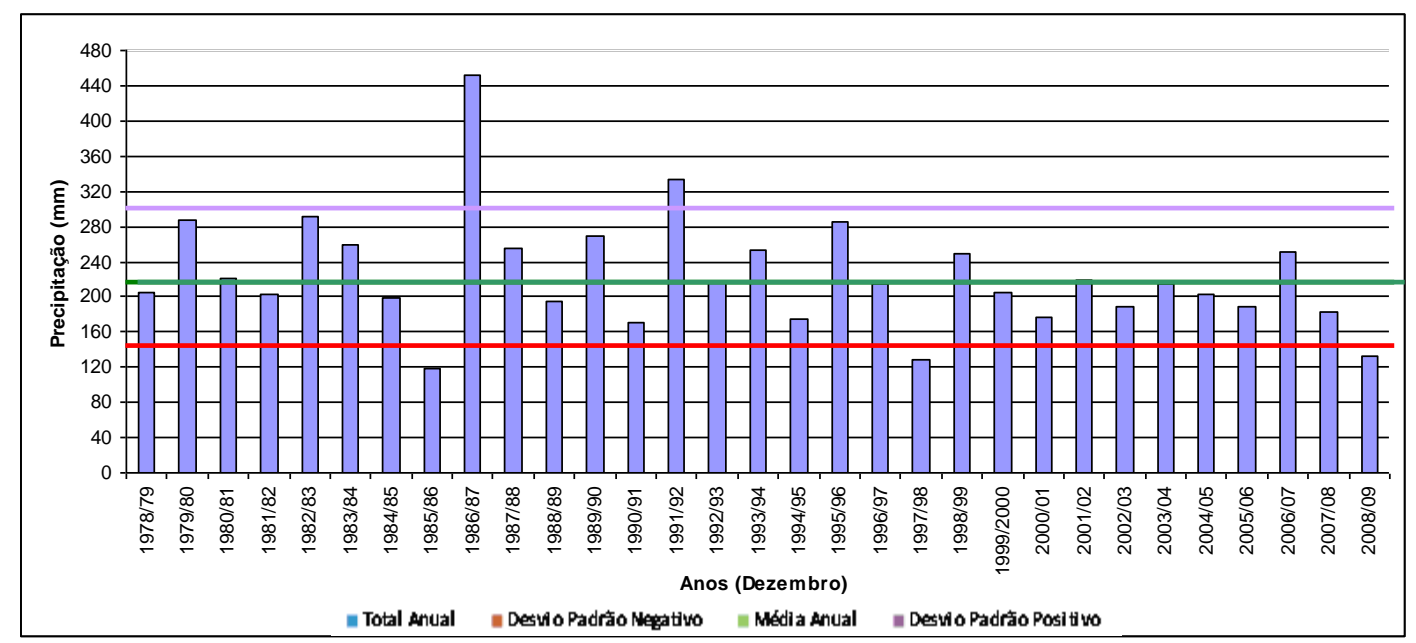

Gráfico 04. Média, desvio padrão positivo e negativo para o total do mês de Dezembro 1978 a 2009. Fonte: IPMet.

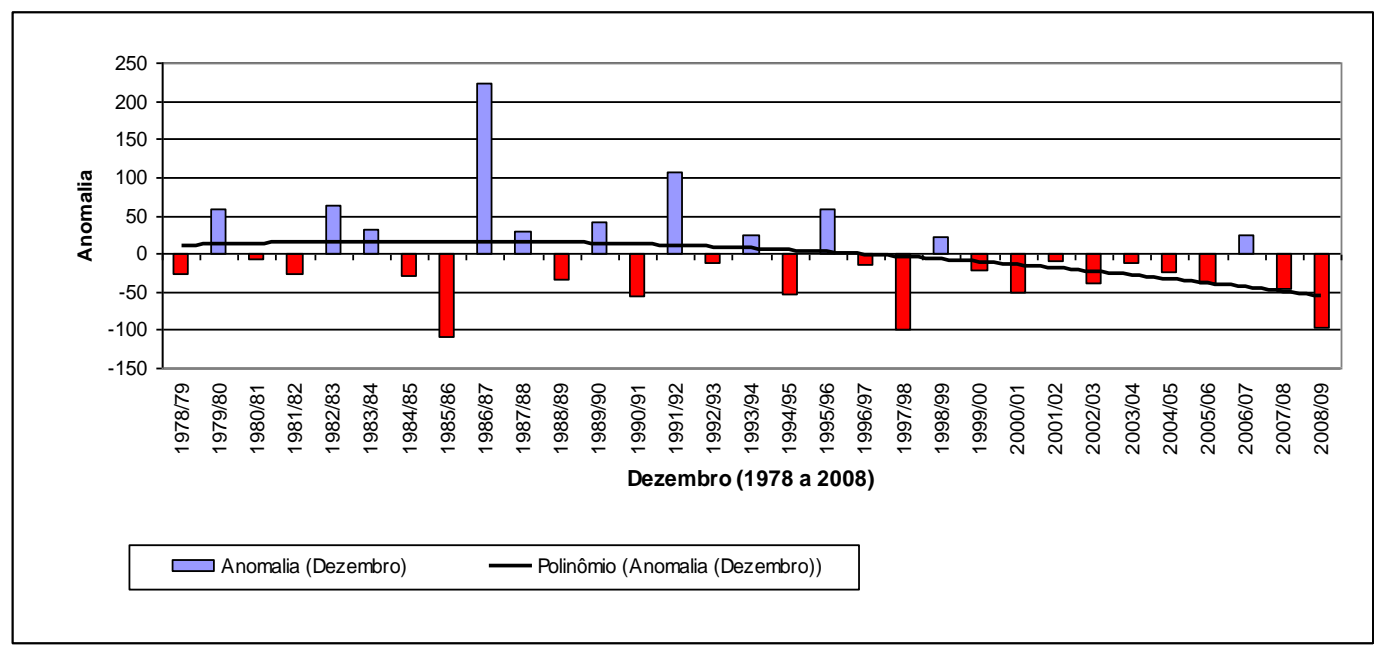

Gráfico 05. Grau de anomalia total do mês de Dezembro de 1978 a 2009. Fonte: IPMet.

Já o mês de janeiro apresentou cinco situações chuvosas, que estão representadas pelos anos de 1982/83, 1988/89, 1996/97, 2002/03 e 2004/05. Conforme a discussão abordada, alguns desses anos foram anos de El Niño-Oscilação Sul (ENOS), influenciando de forma positiva nas variáveis de precipitação, como nos anos de 1982/83, 1996/97 e 2002/03. Observa-se também que o mês de janeiro mostrou-se mais chuvoso do que o mês de dezembro, apresentando também mais eventos de precipitação acima do desvio padrão positivo.

Comparando os dados mensais de janeiro com os de anos padrões de análise, nota-se que todos os cinco anos de situação chuvosa encontrados no gráfico 06 são considerados normais tendentes a chuvoso segundo a tabela 02 .

O gráfico 07, demonstra a anomalia para a serie histórica de Janeiro, a reta de tendência poligonal confirma um leve aumento, e, posteriormente a década de 2000, um leve declínio nos totais de precipitação para o mês nos últimos 30 anos, diferentemente do gráfico 05 
(dezembro), que registrou uma leve tendência a diminuição nos totais de precipitação para o mês de dezembro nos últimos 30 anos.

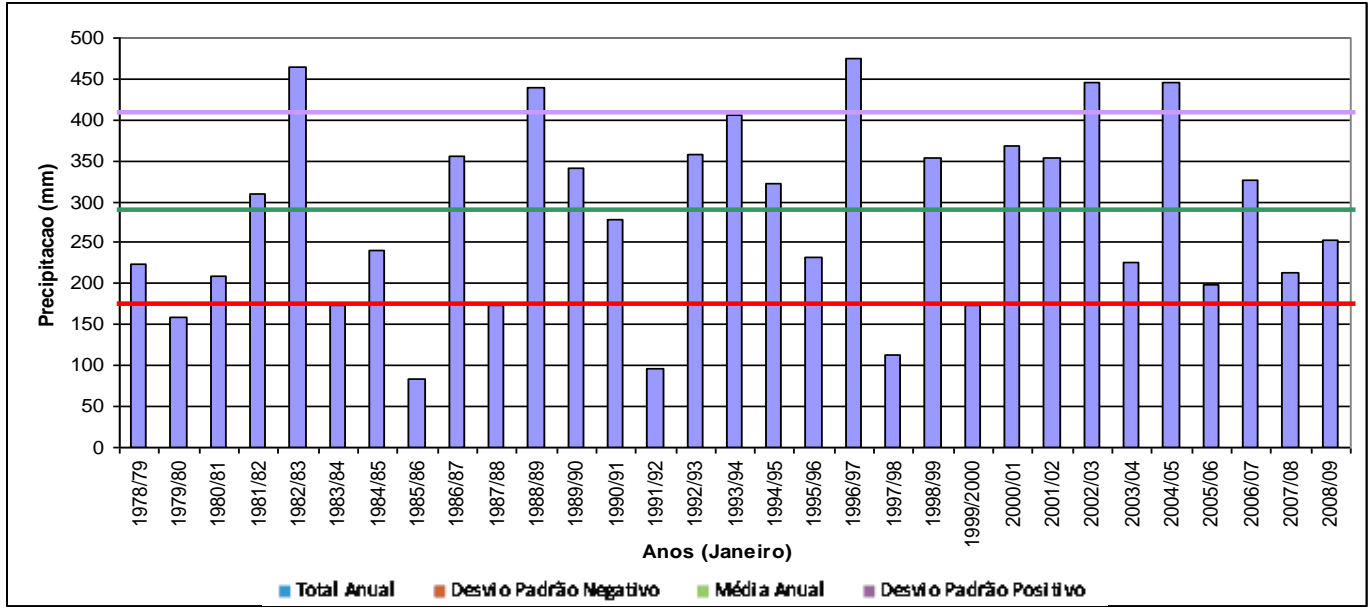

Gráfico 06. Média, desvio padrão positivo e negativo para o total do mês de Janeiro 1978 a 2009. Fonte: IPMet.

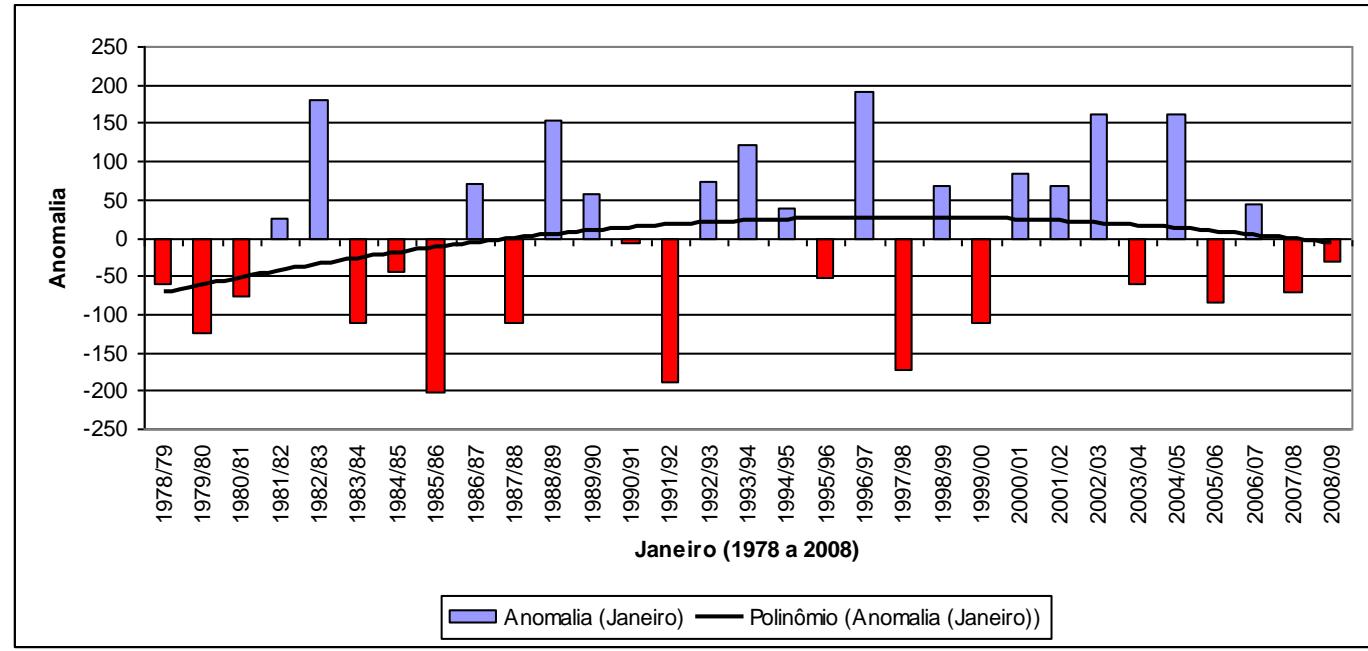

Gráfico 07. Grau de anomalia total do mês de Janeiro de 1978 a 2009. Fonte: IPMet.

O mês de fevereiro apresentou quatro situações consideradas chuvosas, que são os anos de 1992/93, 1994/95, 1997/98 e 1999/2000. Conforme a discussão abordada sobre o El NiñoOscilação Sul (ENOS), apenas o ano de 1997/98 foi influenciando de forma positiva nas variáveis de precipitação. Chama-se a atenção para o fato do mês de Fevereiro ter se mostrado mais seco do que os meses de dezembro e janeiro.

Comparando os dados mensais de fevereiro com os de anos padrões de análise, nota-se que o ano de 1992/93 foi considerado como situação chuvosa e os anos de 1995/96, 1997/98 foram considerados normais tendentes a seco segundo a tabela 02.

O gráfico 09, que demonstra a anomalia para a série histórica de fevereiro, deixa claro que a reta de tendência poligonal confirma um declínio acentuado nos totais de precipitação principalmente a partir da década de 2000, diferentemente do gráfico 07 (janeiro), que registrou um leve aumento, e, posteriormente, um leve declínio nos totais de precipitação para o mês nos últimos 30 anos. 


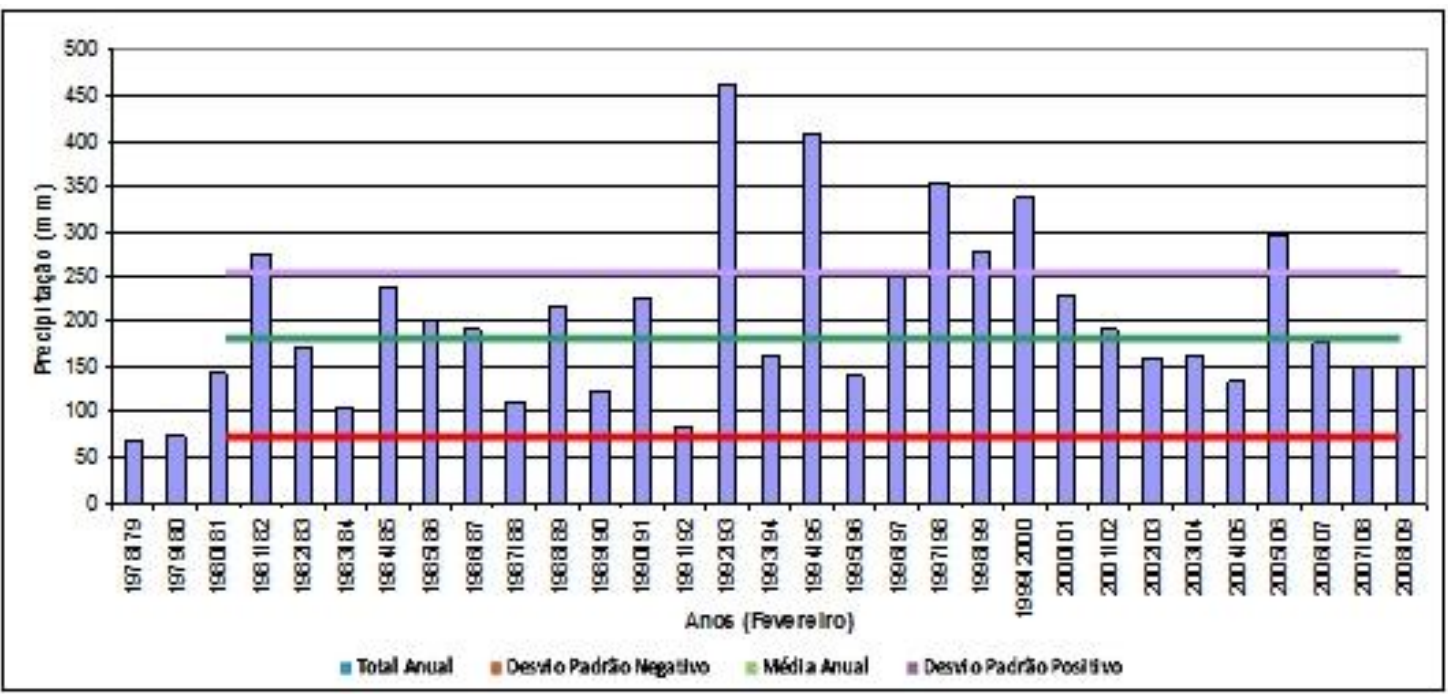

Gráfico 08. Média, desvio padrão positivo e negativo para o total do mês de Fevereiro 1978 a 2009. Fonte: IPMet.

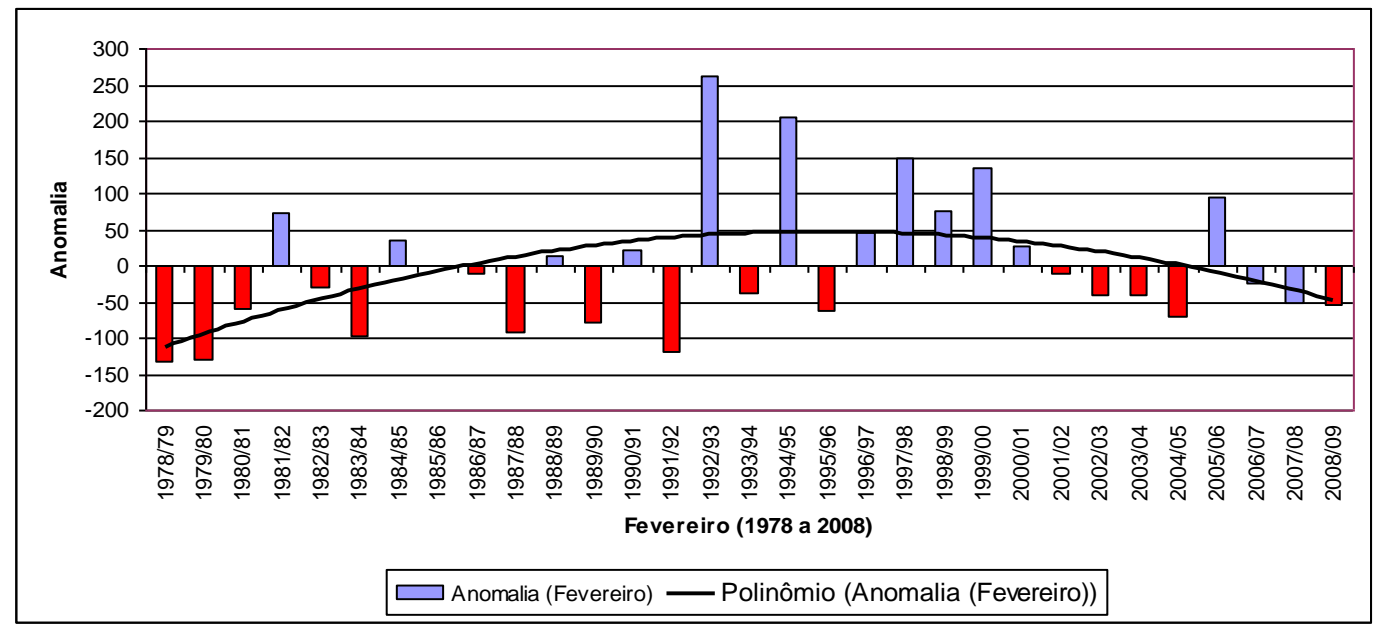

Gráfico 09. Grau de anomalia total do mês de Fevereiro de 1978 a 2009. Fonte: IPMet.

\section{CONSIDERAÇÕES FINAIS}

A cidade de Bauru apresentou para a estação de verão do período estudado uma tendência a diminuição da precipitação a partir do ano de 2000. Já os resultados encontrados na analise da média móvel da precipitação evidenciaram uma leve queda a partir da década de 2000 .

Considerando os meses isoladamente ao longo dos 30 anos estudados, a análise de tendência linear e a de tendência poligonal permitiram visualizar uma variação diferenciada da media móvel, tendo apresentado uma tendência suave ao aumento da precipitação em cada mês, sendo o mês de dezembro o mais típico.

Em relação à elaboração da tipologia pluviométrica de Bauru, observou-se grandes variações rítmicas para os anos de análise e pela maior presença de estações caracterizadas como Normais Tendentes à Chuvosa $(30 \%)$ e Normais Tendentes à Seca $(36,6 \%)$ e logo em seguida, pelas Secas $(23,3 \%)$ e Chuvosas $(6,6 \%)$. A sequência temporal desses tipos pluviométricos apresentou-se com grandes flutuações rítmicas sazonais, configurando-se acentuadas irregularidades das chuvas.

No que se refere aos totais mensais de precipitação do período de estudo, o mês de janeiro apresentou as maiores variações quando comparados aos meses de dezembro e fevereiro, registrando $83 \mathrm{~mm}$ no ano de 1986 e 475 mm no ano de 1997, além disso, evidenciou-se em 
alguns anos, a atuação do ENOS na cidade de Bauru, gerando fortes oscilações nos totais pluviométricos, demarcadas com mais frequência por anomalias pluviométricas positivas.

O mês de janeiro apresentou-se como o mais chuvoso em relação ao seu total pluviométrico para o período, seguido por dezembro e posteriormente fevereiro. O mês de janeiro registrou a maior precipitação mensal no ano de 1997, com o total de $475 \mathrm{~mm}$ de chuva.

Dessa forma conclui-se que houve leve tendência de aumento nos totais de precipitação nos últimos trinta anos de análise a partir da linha de tendência linear, porém em relação a sua media móvel, esta sofreu oscilações ao longo de sua historia principalmente na década de 2000, onde se observou uma ligeira queda. É relevante citar que este aumento não quer dizer, precisamente, que ocorreram mais eventos extremos, mas sim, anomalias que influenciaram, positivamente, as condições pluviométricas no universo de estudo.

\section{REFERÊNCIAS}

.BOIN, M. N. Chuvas e erosões no Oeste Paulista: uma análise climatológica aplicada. 2000. 264 f. Tese (Doutorado em Geociências e Meio Ambiente) - Instituto de Geociências e Ciências Exatas, Universidade Estadual Paulista, Rio Claro, 2000.

.BRASIL. Ministério do Planejamento, Orçamento e Gestão. Instituto Brasileiro de Geografia e Estatística. Base de indicadores socioeconômicos das cidades. Disponível em: <http://www.ibge.gov.br/cidadesat/>. Acesso em: 10 jun. 2007.

.CATELAN, M. J. Expansão territorial urbana e enchentes em Bauru "Os Limites da Cidade "Sem-Limites". (Monografia). Departamento de Geografia da Faculdade de Ciências e Tecnologia da UNESP de Presidente Prudente/SP, para a obtenção do título de Bacharel em Geografia. 2006.

.GONÇALVES, N. M. S. Teoria e clima urbano. Série "Teses e Monografias no 25". São Paulo: IGEOG/USP, 2003.

.LIMA, G. N.; AMORIM. M. C. C. T.Características da temperatura e da umidade do ar em episódios de inverno no município de nova andradina/ms. Anais do XVI Encontro Nacional de Geógrafos - Porto Alegre - 2010.

.MENDONÇA, F.; DANNI-OLIVEIRA, I. M. Climatologia: noções básicas e climas do Brasil. São Paulo: Oficina de Textos, 2007. 206 p.

.MONTEIRO, C. A. de F. Clima e Excepcionalismo: conjecturas sobre o desempenho da atmosfera como fenômeno geográfico. Florianópolis: Editora da UFSC, 1991.

Paulo: IGEOG/USP, 1976.

Teoria e clima urbano. Série "Teses e Monografias no 25". São

.SANTOS, J. A. dos; VITTE. A. C. A atuação dos conselhos municipais em Bauru -SP e o

meio ambiente urbano. Campinas: IG/Unicamp, 2004. 21p.

.SILVA, C. B, SANT'ANNA NETO, J.L e TOMMASELLI, J.T.G. Variabilidade pluviomterica no curso médio do Rio Paraná: área de integração paisagística da "Raia divisõria" SP-PRMS. In Anais do XII Simpósio Brasileiro de Geografia Física Aplicada. Natal (RN). Julho de 2007.

.SORRE, M. A adaptação ao meio climático e biossocial - geografia psicológica. MEGALE, J. F. (Org.). Max. Sorre: Geografia. São Paulo: Ática, 1984.

.TARIFA, J. R. Fluxos polares e as chuvas de primavera - verão no Estado de São Paulo - Uma análise quantitativa do processo genético. São Paulo. Tese (Doutorado em Geografia). Faculdade de Filosófica, Letras e Ciências Humanas, Universidade de São Paulo. 1975. 